\title{
The True Colors of "False" Color: Representing Data Chromatically in NASA Films
}

This paper investigates the multifaceted uses of color - not (only) to aesthetic ends, but as a tool for translating data into narrative - in a corpus of recent NASA films. Often called 'false' color or accused of manipulation, these uses of digital color stray from photorealism but nonetheless have a direct, measurable relationship with physical reality: they use data to render visible that which lies outside the spectrum of visible light. The focus of this paper is on the truth status of these digital films and on the practices used to produce them. It situates them, as a corpus, within and in response to film studies historiographies of color centered around spectacle and the dichotomy of fantasy versus reality, addressing how color can deploy the powers of the false to reveal otherwise invisible truths through art and artifice.

Keywords

COLOR (MEANING AND FUNCTION)

DIGITAL FILM

DATA VISUALIZATION

EPISTEMOLOGY

TRUTH STATUS

INDEXICALITY

NASA

Date submitted: 30/4/2021

Date accepted: 2/9/2021

\section{C.E. Harris \\ ceh@startmail.com}

C.E. Harris is a PhD candidate in Cinema and Visual Studies at Universite de Paris, affiliated with the CERILAC (EA 4410) and LARCA (CNRS UMR 8225) research laboratories. Currently working on a thesis entitled "Spatiality and Mise-en-Scène in Dematerialized Digital Cinema," Harris is interested in film philosophy, aesthetics, phenomenology and the phenomena of cinema, intermediality, and the analogic relationship between science and the arts. 


\section{Scientific images in the Age of Suspicion}

Starting with important 20th century milestones such as the televised footage of the Apollo 11 moon landing and The Blue Marble photograph taken by the Apollo 17 crew, public access to images of outer space has grown exponentially. These images have long been a source of wonder for spectators, but are, at times, also met with a degree of suspicion, particularly as increasingly ambitious space exploration provides ever more spectacular images, and as cross-pollination occurs between the technologies used by scientists and those used by Hollywood, producing vividly colored images often seeming more like science fiction than science fact.

In the digital age, the truth status of images figures perhaps more than ever in public and academic discourse. On the one hand, technologies used to create, enhance, and manipulate images of all registers (Photoshop, CGI) blur the boundaries between image and visualization; live action and animation; the naturalistic, the realistic, and the real. This is not merely an issue of image production but also of reception, as some contemporary audiences seem particularly primed for suspicion and doubt due to growing concerns about fake news, deepfakes, and the manipulative powers of the media, not to mention recent anti-intellectual movements and science denialism. On the other hand, as the digital increasingly eclipses the analog, there is a resurgence of concern for the role and status of photographic indexicality as guarantor of the reality-or the link to reality - of reproductive images.

The question of what it means to capture an image, and by extension, of what precisely an image is in today's media landscape has more urgency than ever. This is true, not only for film and media scholars, but also for practitioners of scientific visualization and imaging, who must reckon with how shifts in media materiality and production processes affect the truth claim and perceived "scientificity" of contemporary scientific images. In other words, the stakes of indexicality extend beyond the bounds of medium specificity or realist aesthetics, into broader questions of credibility and authenticity in terms of how scientific images assert their status as viable scientific objects. This is particularly true for images produced by compiling, transcribing, and translating data into a visual form which exceeds the immediacy and the automaticity of the photographic (for example, in the case of computational images), and which may no longer benefit from an aesthetics of visual naturalism or photorealism to bolster their truth claim. Indeed, as Mary Ann Doane states, "[c]ultural production today seems to be haunted by anxieties surrounding the status of representation in what has been described as our post-medium condition" (Doane 2007, 1). As a result, some of today's most scientifically significant images of outer space, produced through synthetic processes involving multiple technologies, platforms, and practices, have been called into question on precisely these grounds.

There is a sort of double standard that emerges when we set these scientific images in dialogue with other registers of photographic or cinematic images, even fictional ones. Images that rely on the truth claim of indexicality are often subjected to a lower threshold of verification than images which are transparent about their composed, composited, or constructionist nature. Indeed, the hand-drawn or animated infographics which are so common in science communication tend to be judged on the merits of the data that they convey rather than on their 
aesthetic qualities, while imagebased visualizations may also face scrutiny for being too photorealist or not photorealist enough, in addition to being evaluated on their transmission of data. The vast assemblage of choices made by filmmakers of fiction filmsranging from decisions regarding the position of the camera and staging of filmed objects to choices in lenses or lighting to the use of complex editing procedures, for example-may pass imperceptibly or seem less likely to undermine the perceived objectivity of their final product, so long as they uphold a commitment to visual realism. However, scientific visualizations which deliberately make less (or no) effort to disguise their own plasticity or materiality, which choose to forego photorealism in service of a greater transparency regarding their own creation, and which derive their truth claim not from their indexical nature or naturalistic aesthetic but from their reliance on source data as their condition of possibility-in other words, what we might call a "data realism"-are often paradoxically perceived as less objective or less credible because they eschew an aesthetics of visual realism. For example, even images created using technologies like night vision or thermal imaging are often perceived to be less "real" by virtue of their video gamelike aesthetics; studies have shown that, in the context of the military, this can contribute to derealization and dehumanization, and "[generate] psychological distance between the viewer and the viewed" (Vasquez 2008). It is symptomatic of what Doane has called a "politics of the index," in other words, an unintended consequence of the "project of extricating the real from the business of realism" $(2007,4)$.

Indeed, color in particular continues to be disproportionately critiqued in scientific visualizations, especially as compared to other vectors of image manipulation, because it is so easily misconstrued as an embellishment, an enhancement, or a decoration, and because it is so often divorced from the discourse of realism in film scholarship since the age of Technicolor. Where color might be perceived as ostentatious, processes such as stacking, layering, and compositing, for example, are granted greater acceptance, first because they are largely understood as constitutive elements of the final image itself; and second, by virtue of their relative self-effacement. This paper seeks to refute these preconceived notions. It argues that, (1) the association of certain film formal devices such as color with spectacle, artifice, and visual pleasure often leads these devices to be misconstrued as signifiers of fantasy or falsity; (2) by taking into account the datamotivated justifications behind color choices in scientific visualizations, we can situate these films within a larger framework of film color which has always addressed the question of aesthetics versus functionality, on the one hand, and within a larger framework of scientific art which has always linked plastic creation with practices of rigorous observation, on the other; and (3) the aesthetics and functionality of data-motivated uses of color are concomitant in upholding the truth claim of scientific images, which assert their link to reality not via a photochemical imprint of light (classical indexicality) but instead due to the source data that serves as their very condition of possibility (data realism, or data as index).

The comparative angle of this paper seeks to apply these questions - of realism and the fantastical, of the materiality and functionality of the spectacular, and of the truth status of images - to a novel corpus of films for which color plays an integral part. Scientific visualization films employ 
complex chromatic schemata in order to translate arrays of research data into a visually legible form. This paper thus investigates the multifaceted uses of color, not (only) to aesthetic ends, but as a tool for translating data into narrative, in a corpus of recent digital NASA films-Cassiopeia A 3D Model: A Star from the Inside Out (2009), Perpetual Ocean (2011), and Tour of the Moon in 4K (2018)-situating these films within and in response to film studies historiographies of color in order to address how color can deploy the powers of the false to reveal otherwise invisible truths through art and artifice.

\section{"Real" images from space}

In the case of recent digital NASA films, this suspicious reception is at times unintentionally exacerbated by well-meaning explainers produced by specialists in science communication and data visualization. The jargon of image processing itself is often at fault, as some popular audiences have difficulty wresting terms like "false color" or "image manipulation" from their negatively charged lay connotations which seem to imply some form of trickery. This is the case even when such terms are employed in service of explaining their precise mechanisms and field-specific meanings, and even when these explanations explicitly absolve the methods of production in question of any ill intentions or effects.

A notable example of this is a short science communication video that was released to mark the occasion of NASA's updated Blue Marble 2012 image of the Earth captured by its Suomi NPP satellite in 2012. This image, like myriad others of its genre, is not exactly a photograph; it was produced through a complex process of compositing in which a series of high-resolution slices were digitally stitched together and enhanced to form a single view of our planet. Shortly after its release, Flora Lichtman of NPR's Science Friday recorded an interview with NASA/Goddard Space Flight Center visualization specialists Gene Feldman and Robert Simmon entitled "Blue Marble:The Making Of."2 The goal of this interview was twofold: first, to situate the Blue Marble 2012 image within the larger context of previous "portraits" of Earth taken from outer space, and second, to explain the technical processes used in the capturing and processing of these images for lay audiences. Feldman and Simmon describe the various image processing procedures - from techniques like stacking, layering, and compositing, to the removal of gaps between slices in the source material using Photoshop, to adjusting and enhancing elements like color and transparency in the composited image-which are typically used in preparing NASA images for public release.

This effort toward transparency was met, however, with an unexpected backlash. In 2014, the "Blue Marble: The Making Of" video was re-posted on YouTube using the title "NASA ADMITS THEY DONT USE REAL IMAGES FROM SPACE" (sic) and with the description, "SPACE TRAVEL IS NOT POSSIBLE WHY DOESN'T NASA HAVE HUNDREDS OF ACTUAL IMAGES OF EARTH FROM SPACE? WHY ARE THEY PAYING ARTISTS MONEY TO RE CREATE EARTH IN THEIR OWN VISION THROUGH PHOTOSHOP?" (sic) by user leucotomy 101. ${ }^{3}$ Under the video hundreds of YouTube users posted comments of a similar ilk, decrying supposed NASA fakery and spreading the rhetoric of popular conspiracy theories. What is striking about this video-which is by no means unique in its genre (and setting aside debates of whether the post and subsequent comments were made in good faith 


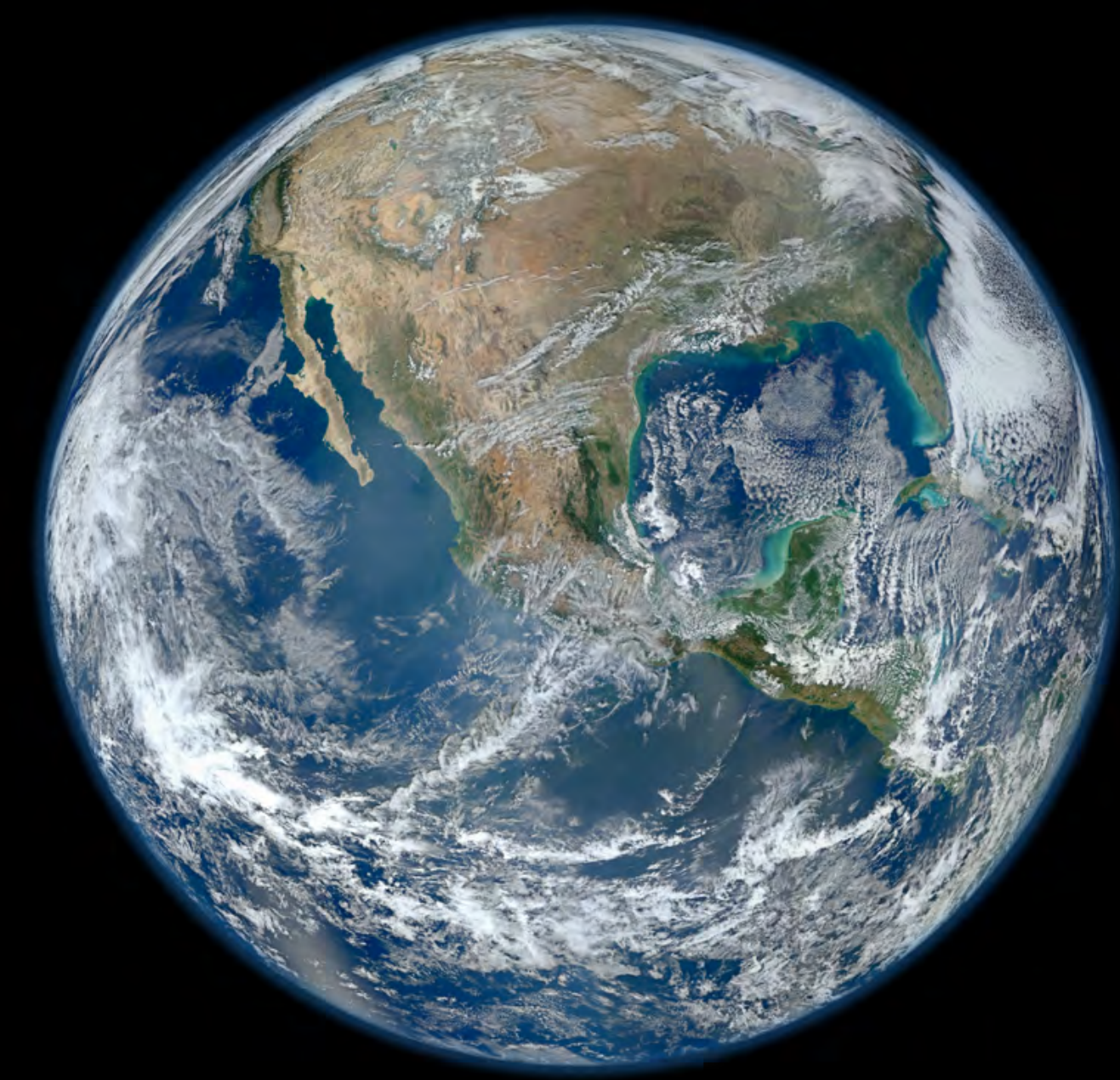

Fig. 1: Blue Marble 2012 (NASA/NOAA/GSFC/Suomi NPP/ VIIRS/Norman Kuring, 2012) 
ignorance or as an Internet trolling scheme)-is the fact that, other than the re-titling and new description of the post, it makes no attempt to alter, analyze, or annotate the original video's content in any way. Its poster and commenters rely exclusively on the charged connotations of the original video's terminology - the very mention of image manipulation, the very mention of Photoshop-to do all of the work of their "gotcha"-style exposé. The absence of photographic indexicality is invoked as a marker of inauthenticity (though, of course, not in so many words), as the description and comments question why NASA does not simply release raw point-andshoot photographs of the Earth rather than "paying artists," implying that the plastic nature of these imagesregardless of how transparently they are presented or explained-is in and of itself evidence of falsification or trickery.

This suspicious reception of images produced by astrophotography or by scientific visualization is neither recent nor uncommon. It seems to have gained momentum since the early 1990s with the Hubble Space Telescope's launch and ensuing public relations campaign, during which science communicators had the momentous task not only of explaining the images it produced, but also of reasserting the credibility of Hubble's images following the discovery and repair of the telescope's initial mirror defect. While damage control was largely successful, a negative response nonetheless remained, not resulting from the resolved defect, but instead due to the spectacular quality of the images that it produced. The fantastic colors of images like Hubble's 1995 Pillars of Creation were a source of wonder, but precisely due to their beauty, they were often dismissed as scientific objects. In Coloring the Universe (2015), Travis Rector, Kimberly Arcand, and Megan Watzke explain that this was the case even among some members of the scientific community: "Many scientists labeled the Pillars of Creation, and other images like it, as 'pretty pictures' - and not in a complimentary way" $(2015,61)$, as they saw the use of the telescope for the explicit goal of producing color images for public release as an infringement on telescope time that could otherwise be used to produce data for scientific purposes. Rector, Arcand, and Watzke go on to detail precisely how the fantastic colors of these images come about in the production process, notably arguing that their spectacular nature is not at odds with but rather reaffirms their scientificity. Hubble's narrowband color filters were chosen and calibrated such that they could best convey data about the different temperatures and elements present in cosmic bodies $(2015,122)$. Indeed, NASA's Jet Propulsion Laboratory confirms that, in Pillars of Creation, red corresponds to singly-ionized sulfur atoms, green corresponds to hydrogen, and blue to doubly-ionized oxygen atoms (NASA Jet Propulsion Laboratory 2005). The vivid colors of the image are not mere aesthetic embellishments, but functional data points; spectacular images like Pillars of Creation forego visual naturalism in favor of a data realism that instrumentalizes color to express scientific information. Today's "real images from space" are decidedly constructionist and rarely purely photographic; due to their reliance on source data, they retain a direct relation to the reality of the objects that they represent.

\section{Film color: aesthetics versus function}

There is a certain tradition of film theory that has understood the uses of cinematic color in mainstream narrative film as a site of spectacle and visual pleasure, on the one hand, and as a visual shorthand for 


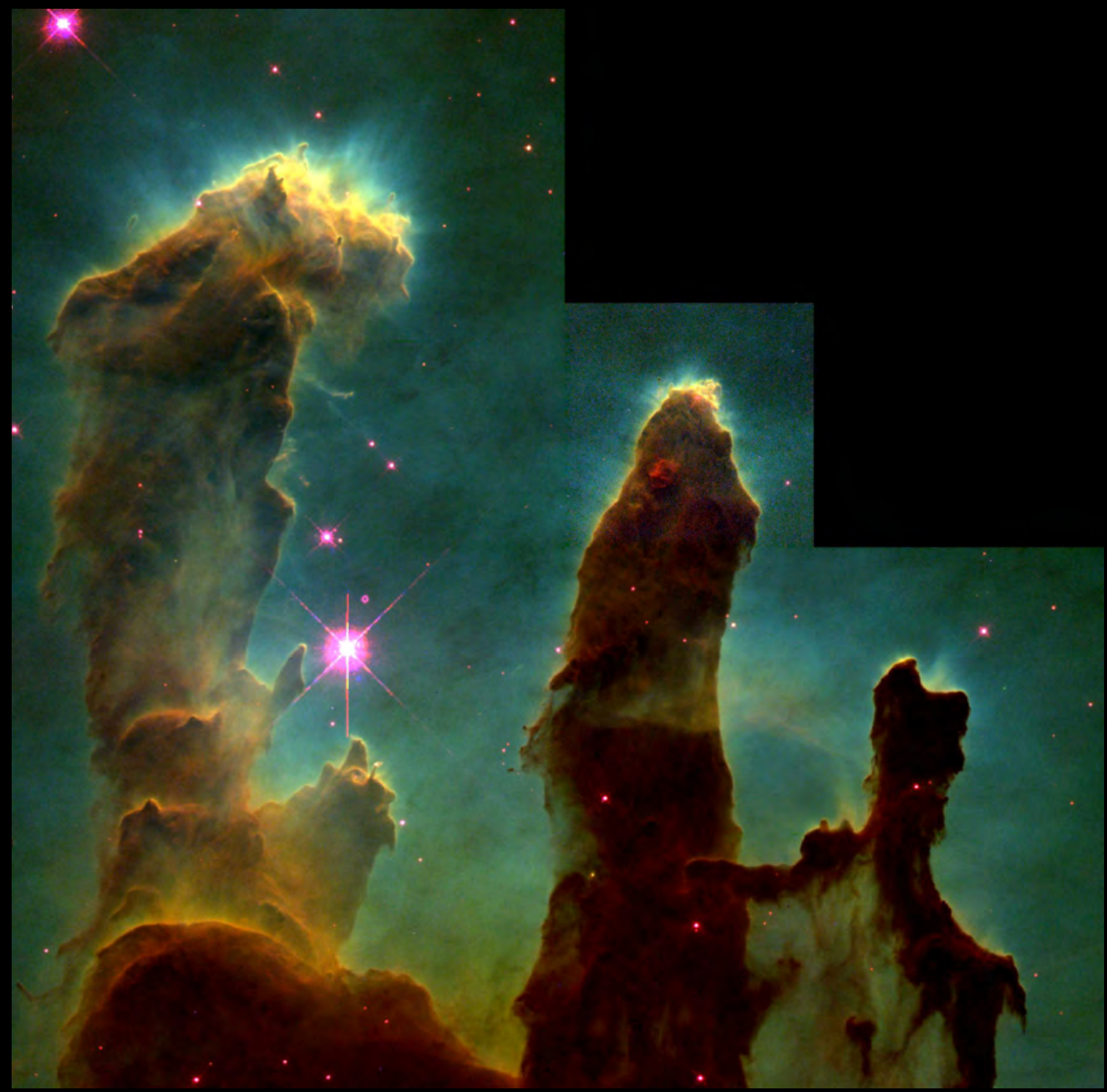

Fig. 2: The Pillars of Creation taken by the Hubble telescope (NASA/Jeff Hester/Paul Scowen [Arizona State University], 1995) 
distinguishing between different registers of images, on the other. ${ }^{4}$ In the early period, hand-painting techniques or the tinting of specific portions of film stock-from Annabelle Butterfly Dance (William Kennedy Dickson, 1894) to The Lonedale Operator (David Wark Griffith, 1911)—contributed to the visual fascination characteristic of the cinema of attractions. In classical cinema, color could be invoked as a fanciful or fantastical counterpoint to the realism of black and white images, even expressionistically enhancing the emotional content or arc of films, as in the practice of Golden Age melodramas with their use of Technicolor. As color films eclipsed black and white, specific chromatic palettes and uses of lighting often took on a functional role toward the guarantee of continuity, used to set apart, for example, flashback sequences from otherwise linear film chronologies, rendering jumps in time or space more visually transparent for spectators. Finally, in recent years, the use of particular color palettes has even been described as a matter of zeitgeist, as in the case of the oft-cited Hollywood predilection for teal and orange color grading in the 2000s, for example (Miro 2010).

While this is admittedly a vast over-simplification, it serves simply to highlight a long-standing tradition of linking cinematic color-and the material nature of the cinematic spectacular writ large-to questions of realism versus fantasy, and of form versus function. Film devices that do not fit neatly into the constitutive formal categories of cinematography, mise en scène, and editing-such as music or colorare particularly susceptible to these debates, sometimes being reduced to an aesthetics of the decorative or to a functionality of emotional manipulation. However, as outlined in the following section, aesthetics and functionality need not be seen as diametrically opposed. Indeed, in the case of scientific visualizations, there is a much longer tradition of linking art and plasticity to the pursuit of intellectual rigor through the observation and transcription of the qualia of scientific objects.

\section{Artistic vision in the service of astronomical knowledge}

The scientific field of astronomy has two primary branches: observational astronomy, in which data is collected through direct and indirect observation of astronomical objects and phenomena; and theoretical astronomy, which attempts to describe and explain these objects and phenomena through mathematical, statistical, analytical or computer modeling. What unites these two branches, in addition to their common objects of analysis, is the complementary nature of their epistemological approaches. As film and visual studies scholars, here we can see a clear parallel to the cinema, with its realist and its constructionist pasts: together, they record images of reality, and also create images to describe what that reality might entail. Of course, the term "images" is being used here in the broadest possible sense, in order to account for the fact that scientific imaging does not always operate within the realm of the optical, the photographic, or even the visual. Nonetheless, of particular relevance here is the notion of scientific knowledge acquisition through the production of images as both observational and creative.

Art historian Elsa De Smet traces a history of this epistemological stance in astronomy back to the 17th century, in which there was a forthright link between science and art. Describing Galileo as "the defender of a necessary coalescence between aesthetic attitudes and scientific thought,"6 she goes on to explain that "this Galilean 


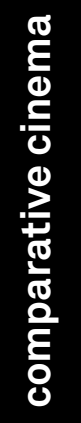

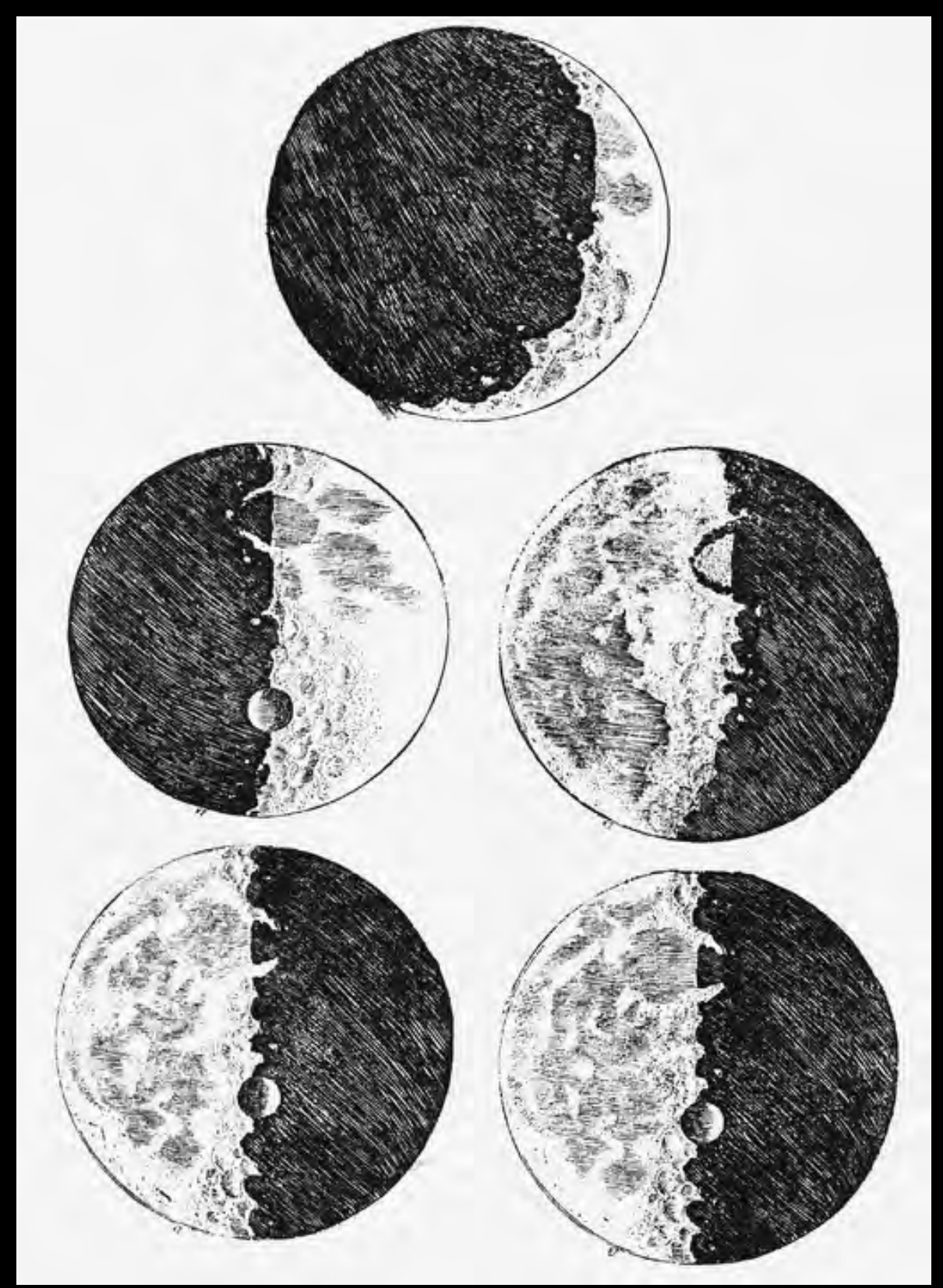

Fig. 3: Galileo's sketches of the Moon (Sidereus Nuncius, 1610) 
tradition of artistic treatments of outer space-pictorial, naturalistic, figurative, and picturesque in naturewhich make[s] art of scientific content in order to render it intelligible" 7 persisted well into the 20th century (De Smet 2017, 22). She also cites Johannes Kepler, who "turned toward fiction as a "cognitive vehicle"" when he wrote his novel Somnium (in English: The Dream, or Posthumous Work on Lunar Astronomy, 1608, published 1634). Despite being a work of fiction, it has long been lauded for the rigor of the thought experiment that it conducts as a means of thinking through what it might entail to conduct serious astronomical study from the Moon rather than from the Earth.

This tradition of artistic science and plastic observation - of conducting serious and rigorous astronomy research that relies on fiction, painting, drawings, etchings, dioramas, etc.might seem anachronistic today, especially as the hard division between STEM disciplines and the humanities is reinforced institutionally, financially, and even politically. However, in many ways, astronomy is resisting this tendency, asserting its interdisciplinary character more than ever. In 2016, Lisa Messeri, an anthropologist of science and technology at Yale University, published her monograph Placing Outer Space: An Earthly Ethnography of Other Worlds. In this work, she describes how the field of planetary science is migrating more and more toward what she calls "the new interdisciplinary science of the solar system" (2016, 5). She situates this shift as a logical extension of a long history of regarding scientific objects from both "realist and constructionist approaches," in other words, by considering objects not only as "discoverable" but also as "inventions[, as] things molded from a historical and local context" $(2016,8)$. It is in this light that scientific objects can-and must-be considered not only (or primarily) as realia, but also for how they "embody what one does not yet know" (Hans-Jörg Rheinberger, quoted in Messeri 2016, 9), in order to give rise to an approach of doing science that legitimizes "experimental ways of knowing" (2016, 12). For Messeri, this extends beyond the first degree of bridging the socalled hard sciences with fields like sociology, anthropology, and cultural geography; it also entails what she refers to as "planetary imaginations" $(2016,9)$, which take seriously the constructionist methodologies of simulation, visualization, modeling, and creative imagination as a means of doing science.

Indeed, there has been a recent boom in interdisciplinary re-thinkings of scientific epistemology through the humanities and the arts. National and international scientific organizations like NASA or the European Space Agency (ESA), for example, now have entire branches dedicated to outreach, targeting new audiences (non-STEM university researchers, citizen scientists, as well as the public at large) often by explicitly linking the study of science to the arts. To this end, they employ and engage with artists, animators, visual designers, science communicators, philosophers, sociologists, and scholars of the digital humanities, among others. In 2000, the French government's space agency, the CNES (National Center for Space Studies), created a cultural laboratory invested in space art, as well as a subdivision called "Spatial Humanities" (humanités spatiales) dedicated to bringing together humanities scholars that study outer space, its objects, and its representations, whether "scientific, artistic, literary, audiovisual, etc." (Humanités Spatiales, n.d.). NASA has also increasingly formalized its efforts to engage with artists who work in the fields of digital animation and visualization in order to collaborate on 
several of their most important-and award-winning-outreach projects of the past few years. This is not only for public outreach or educational purposes, but is also an increasingly important tool for the processing of collected data. NASA scientist Gene Feldman, who has participated in many of these visualization collaborations, has said, "[b]ecause the data volumes that we get from space now are astronomical, the only way that we can really handle this anymore is to visualize it. And no matter what computers we may build, the human mind and the human eye, in my mind, is (sic) still the most powerful integrator of information" (Feldman and Simmon 2012, my italics). It is precisely this genre of visualization-visualizations created in the service of processing and deciphering data-that is the object of the three case studies presented below.

The three films that this paper is concerned with have been chosen for their innovative digital treatments of color. These are not always naturalistic, but they are pictorial, figurative, and picturesque in nature, and above all, they are firmly engaged in a project of making art of scientific content in order to render it intelligible not only to the general public and education audiences, but even to research scientists themselves. The subsequent analysis attempts to tease out a new paradigm of digital color use in films which relocates the digital from an additive or supplementary element of editing (or a package for distribution) to the very basis of their production. In other words, today the digital does not simply replace or enhance elements within an image, but is now able to construct the image itself from the ground up using data as its foundation. ${ }^{9}$ As computer-generated, data-driven computational images become increasingly ubiquitous in our media landscape, we must consider how they relate to prior traditions of scientific observation and plastic epistemologies, and how they can help us look to the future, beyond paradigms like the hegemony of the optical ${ }^{10}$ and the primacy of the photographic index, as they render visible facets of reality to which we have previously had little or no prior access.

\section{Tour of the Moon in 4K (2018)}

The culmination of nine years of data collection, Tour of the Moon in $4 K$ was released by NASA's Scientific Visualization Studio in 2018, and is a hybrid film on multiple levels. ${ }^{11}$ First, it uses photographic images captured by the Lunar Reconnaissance Orbiter (LRO), stacked and stitched together to create a seamless 360-degree representation of our moon in high resolution. Secondly, the visualization is animated by reconstituting the LRO's actual flight paths, in order to create a spatially realistic fly-over. Finally, "false" color-color that does not correspond to what the naked eye would perceive-is added to the images in order to reveal data points that would otherwise be invisible. At 43 seconds into the visualization, an otherwise photorealist image of the moon, with all of its topographical detail, lights up in bright colors to highlight a variety of data points taken at precisely chosen landmark locations. These colors are accompanied by a key, superimposed over the top right-hand corner of the image or by a voice-over narration, which explains the units of measurement of the specific data points being visualized by the digitallyadded color, as well as a numeric indicator which ascribes particular colors to each numeric range for easy deciphering.

First, we are shown the free-air gravity measurement (in mGal units) of the Orientale Basin in a sequence that digitally paints the moon in vivid 


\section{Orientale Basin}
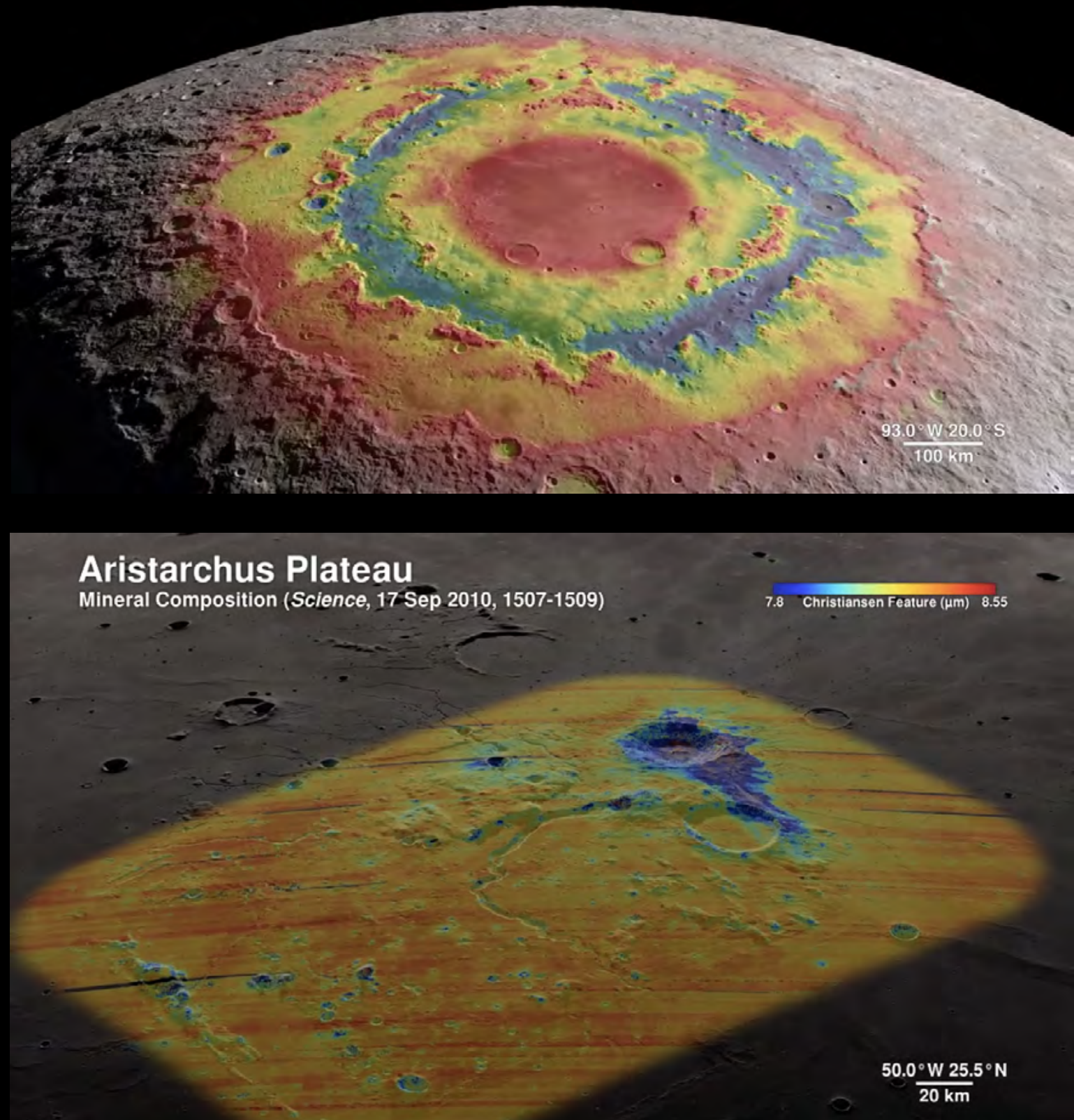

Fig. 4.

Top: The Orientale Basin in Tour of the Moon in 4K (NASA's Scientific Visualization Studio/NASA's Goddard Space Flight Center/David Ladd \& Ernie Wright, 2019)

Bottom: The Aristarchus Plateau in Tour of the Moon in $4 \mathrm{~K}$ (NASA's Scientific Visualization Studio/NASA's Goddard Space Flight Center/David Ladd \& Ernie Wright, 2019)

\section{$\times \mathrm{x}$ s.}



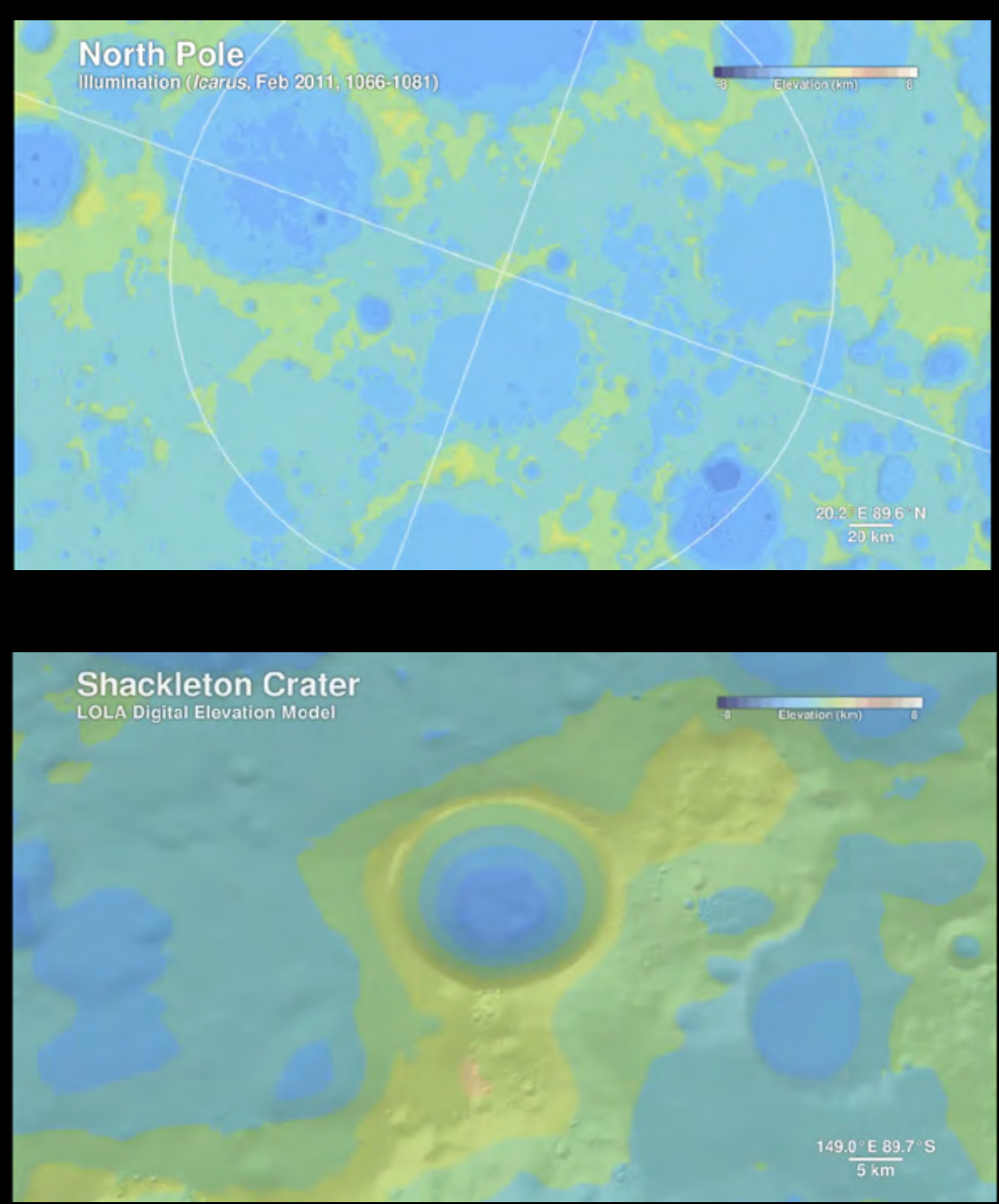

Fig. 5.

Top: The North Pole in

Tour of the Moon in $4 \mathrm{~K}$

(NASA's Scientific

Visualization Studio/

NASA's Goddard Space

Flight Center/David

Ladd \& Ernie Wright, 2019)

Bottom: The

Shackleton crater in Tour of the Moon in $4 \mathrm{~K}$ (NASA's Scientific

Visualization Studio/ NASA's Goddard Space Flight Center/David Ladd \& Ernie Wright, 2019)
Fig. 6.

Top:

The North Pole without color in Tour of the Moon in $4 \mathrm{~K}$ (NASA's

Scientific

Visualization

Studio/NASA's

Goddard Space

Flight Center/

David Ladd \& Ernie Wright, 2019)

Bottom: The South Pole without color in Tour of the Moon in $4 \mathrm{~K}$ (NASA's Scientific Visualization Studio/NASA's Goddard Space Flight Center/ David Ladd \& Ernie Wright, 2019)

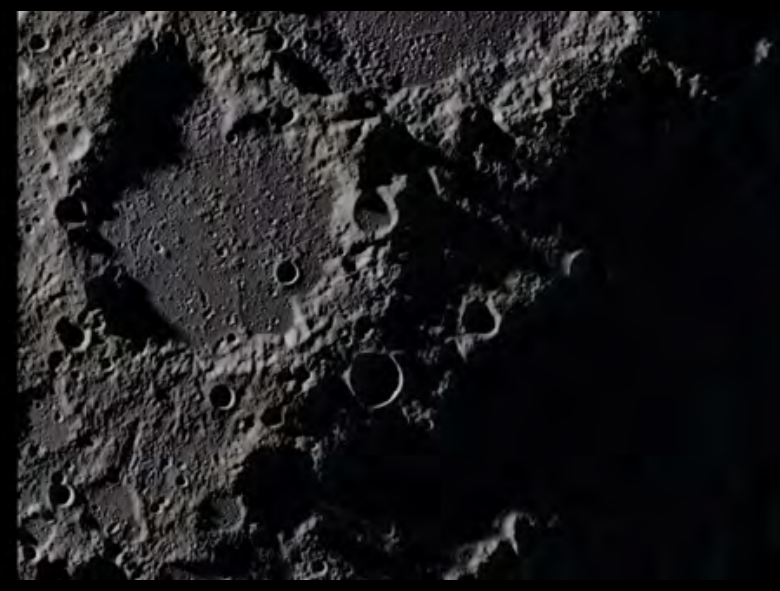

${ }^{9.3^{\circ} \mathrm{E} 90.0^{\circ}}{ }^{20 \mathrm{~N}}$

\section{South Pole}

Surface Water Ice (Icarus, Aug 2017, 74-85)

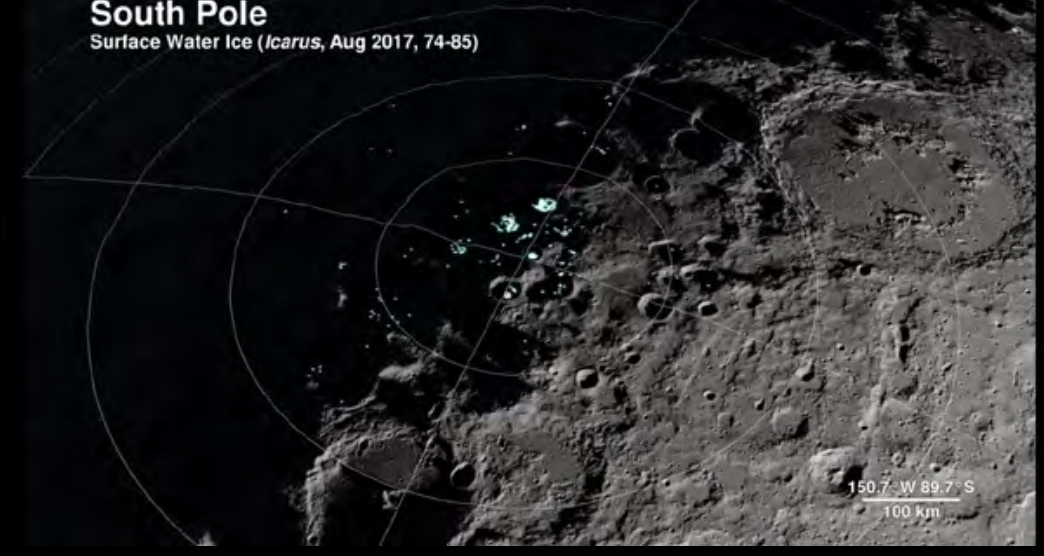


reds, yellows, blues, and greens and highlights the structure of the moon's crust. We are then "flown" to the moon's South Pole, which appears speckled with teal in varying degrees of brightness; the location of the colors corresponds to the location of polar ice troves discovered on the moon's surface, and the brightness of the colors here indicates quantities and temperatures, as measured by temperature readings and reflectance from the LRO's instrumentation.

Digital elevation models of the Shackleton Crater appear in pastel blues, yellows, and greens, whose gradient corresponds to variations in elevation measured in kilometers. From here, the simulated LRO zooms out to reveal a brightly colored topographical map of the entire moon, in order to render visible the immensity of the Aitken Basin crater through chromatic contrasts with surrounding geographies. The Aristarchus Plateau is highlighted in a rainbow of colors to reveal the presence, location, and concentration of mineral deposits in order to detail the volcanic history of the moon. In the Taurus-Littrow Valley, blue, green, and orange lines superimposed over present geological features highlight the Apollo 17 travel pathways in accordance with locations and times. These digital color visualizations are always superimposed over a photographic 3D reconstitution of the moon's surface, and are often interspliced with photographic inserts which show magnified detail of specific points and locations, even including images of the current location of the lander and rover of this mission which were left behind. Finally, we are taken to the North Pole to explore an area devoid of sunlight due to the moon's tilt. Bright blues and yellows reveal crater rims and topographical features which would otherwise be invisible to our optical instrumentation due to the permanent absence of light in this location. Data collected by non-optical measurements is rendered visible only through this use of color.

At first glance, this visualization seems to fit into a "classical" paradigm of digital film production, with liveaction images which were first recorded and then supplemented by CGI. However, the use of color here is more complex than that. It is precisely not what William Johnson calls "decorative color," in other words, color serving as a "decorative wrapping that adds pleasure to a film" (Johnson 1966, 8). Color, here, does not merely enhance the image; it is not intended-like other classical uses of $\mathrm{CGl}$ - to contribute to its photorealism by adding in highquality visual elements that would otherwise have been difficult to film; and it does not serve as a corrective for a faulty image. In fact, it is quite antirealist in terms of the visual aesthetic it creates. Instead, it is a means of translating data into a visually accessible form, revealing measures and information that would otherwise be inaccessible, and mapping them such that it becomes clear how each data point relates to the others. What starts as a form of cartography winds up providing a whole new context through which the original moon image used in this film-under its layers of CGI colors-becomes legible. In short, color does not simply add another element to the image, but another means of reading the image entirely.

\section{Cassiopeia A 3D Model: A Star from Inside Out (2009)}

Cassiopeia A 3D Model: A Star from Inside Out, produced through a collaboration between teams from NASA, the Chandra X-ray Center, and MIT, was released in 2009 and visualizes data collected between 2000 and $2007 .^{12}$ What is immediately obvious in watching this visualization is its complete lack of photorealism. The 
glowing object in the foreground is an artist's digital rendering of a rotating supernova remnant-the remains of a star which exploded approximately 330 years ago. As the simulated camera "dollies" backward to show the remnant in its immediate cosmic environment, we see what appear to be multicolored clouds of varying opacity-red, green, yellow, and blue-revolving around this remnant while the simulated camera, in turn, arcs around the cluster, seeming to pass through the clouds. Faint stars dot the black void of space, making up the background of the image as points of reference that render legible the flurry of circular movements that we see. From an aesthetic point of view, these images in no way resemble what we might expect from a visual document of an astronomical object, and instead evoke an aesthetics of spectacular fantasy or science fiction.

This 3D model is a digital animation produced using a combination of commercial (Hollywood) software and a 3D slicing program originally used in medical imaging that was modified for NASA's use by Harvard University (Chandra X-Ray Observatory, n.d.). But despite its fanciful appearance, I want to insist on its realism-not, obviously, a photorealist or naturalistic realism, but a data realism. On the Chandra X-Ray Observatory Center's website, where we find the publication of this visualization, we are invited to compare the digital imagery to other images of what Cassiopeia A might look like to the naked eye-or at least to a telescope viewing it in the visible light spectrum - and what it looks like using other forms of non-optical data. A sideby-side comparison is available using real optical light images created by the Hubble Telescope, the Digitalized Sky Survey, and other sources. These images impress upon us the stark difference in aesthetics and serve to highlight the fact that optical light imagery is precisely not the source material—or the target goal—of this visualization.

Instead, the 3D model was built by layering data sets recorded outside of what human vision can perceive and then translating these into faithful visual representations. First, multiple levels of X-ray energy were recorded in three colors: blue is used to represent high energy $X$-Rays, green corresponds to medium energy $\mathrm{X}$-Rays, and red corresponds to low energy X-Rays. These images were then combined digitally. Kimberly Arcand, the visualization lead for NASA's Chandra X-Ray Observatory, explains this process by showing images of each step of the process in her 2018 talk, "Exploring Hidden and Exotic Worlds: How Astronomical Data Transports Us," and in its accompanying visual materials available online (Arcand 2018). The Chandra website also includes a detailed explainer which offers a key to further color usages and nuances, highlighting how the final product of the visualization uses color to show not only X-Ray data, but also infrared data whose colors correspond to different elements (argon, silicon, iron) present in the Cassiopeia $A$ cloud cluster, as well as synchrotron radiation (Chandra X-Ray Observatory, n.d.). Because the original data lies outside the spectrum of visible light, it is functionally invisible to the human eye and to natural light optical devices. By translating non-optical data into visible light and color, scientists studying these cosmic bodies are able to literally render visible what would otherwise be invisible (Arcand 2018). Since the color attributions do not correspond to the visible light spectrum, they are what some have called "false color," assigned based on choices made by the visualization specialists in order to most clearly convey the desired information and messages of the visualized data. 


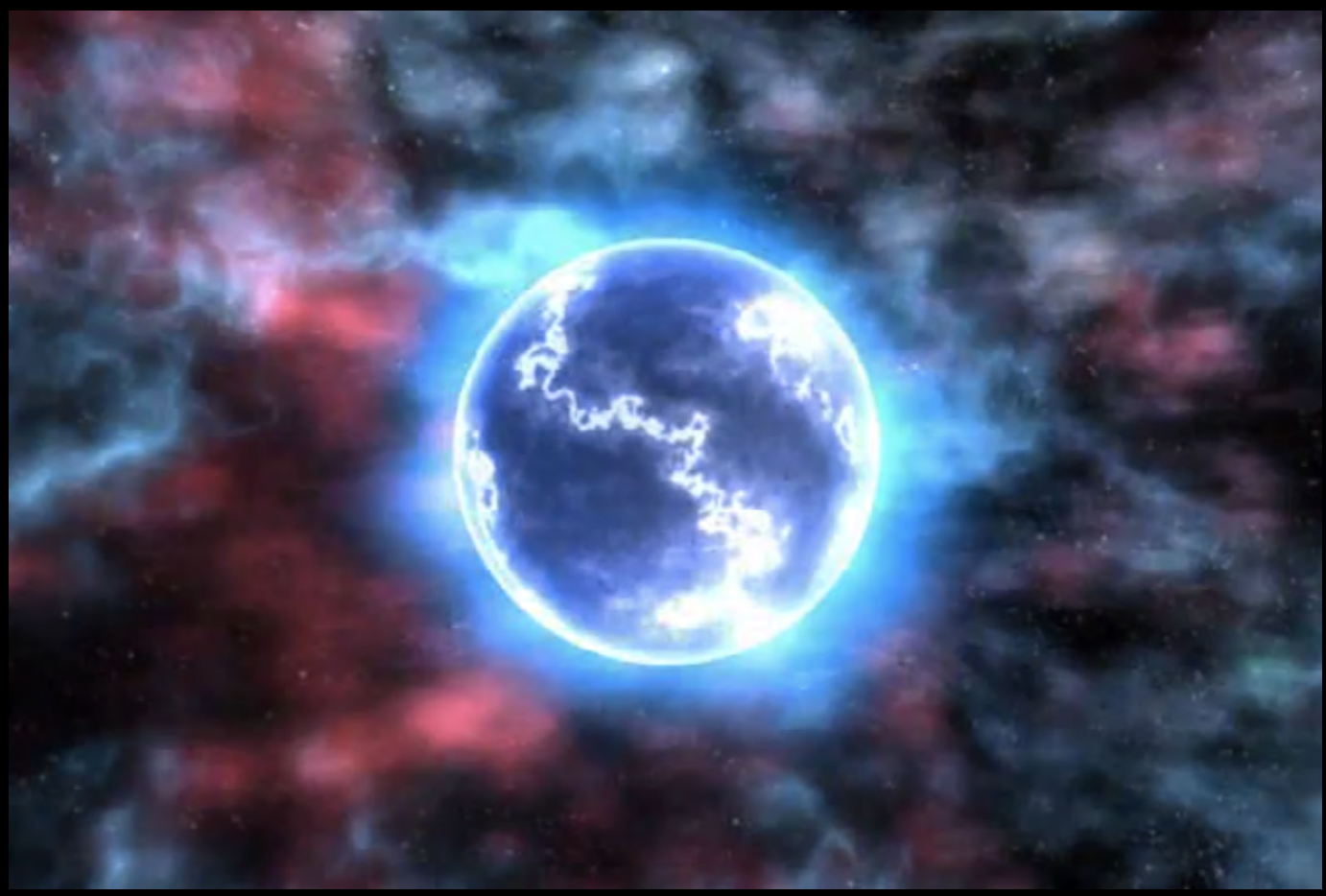

Fig. 7: Cassiopeia A in Cassiopeia A 3D Model: A Star from Inside Out (Visualization: NASA/CXC/D.Berry; Model: NASA/CXC/MIT/T.Delaney et al., 2009) 
However, in a talk entitled "The Art of Science Visualization," Robert Hurt, a visualization specialist for NASA's Spitzer Space Telescope Science Center, explains how terms like "false color" and "colorization" are misnomers in this context:

False color [is] a term that had a purpose [...] when almost every photo you ever saw was a photo of representing the way light hits the eye. They needed a way of calling out images that have been processed in some other way. [...] But it carries with it a horrible connotation that we are doing something wrong with the imagery and somehow these colors aren't real. Instead I like to divert people to [terms] like representative color [or] translated color [... as] most of the spectrum of light is at wavelengths I can't see. So we want to take those colors that are real at other parts of the spectrum and translate them into the red, green, blue that our eyes can see. [These colors] aren't false. They're only misunderstood. (Hurt 2018)

Here the use of color is translated and representative, a package for conveying data by visual means. This data, translated into color, is compiled, layered, and then digitally rendered in three dimensions in order to allow scientists to render visible what our naked eye would otherwise be unable to perceive. Color here is the visualization of data sets outside of the optical realm.

\section{Perpetual Ocean (2011)}

Finally, Perpetual Ocean is a 2011 visualization created from data collected between 2005 and 2007 in an ambitious NASA-MIT collaboration..$^{13}$ According to NASA, it is "based on a synthesis of a numerical model with observational data [...] in order to obtain realistic descriptions of how ocean circulation evolves over time. These model-data syntheses are among the largest computations of their kind ever undertaken" (NASA 2012). Indeed, one of the primary functions of this visualization was to render intelligible data from several extremely large data sets that would otherwise be unwieldy to work with, even for the scientists compiling them. The Estimating the Circulation and Climate of the Ocean (ECCO) data set parent directory reveals roughly 30 distinct sets of measures and variables that were studied and compiled into massive data arrays; each array appears to contain little more than thousands of strings of numbers off-set by commas, and is entirely opaque to the uninitiated expert. These data sets are made publicly available by MIT, and simply perusing them highlights the complexity, despite whatever precision this data contains, of the vertiginous task of rendering its data intelligible and even useful (ECCO Group 2007). The Perpetual Ocean visualization effectively translated millions of individual data points into legible, dynamic computational models of the oceans, winds, currents, and ice around the world, including the interaction of effects of currents like the Gulf Stream, average monthly temperatures, and ocean salinity, among others. According to Earth scientist Ying Fan, through this simulation, "we are able to set the atmosphere and the ocean into such magnificent motions based on a few conservation laws and a set of empirical relations, and by doing so we are able to construct a crystal ball [...] and gaze into the past and the future of this planet" (Fan 2015, 3053). The data is the primary material that constitutes the visualization; with its precise measures and variables dictating how the visualization looks and behaves, it can grant us access to verifiable information about our planet.

Once again, the film is decidedly not within the realm of the naturalistic or photorealistic. If the Cassiopeia $A$ 


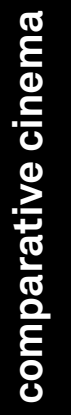

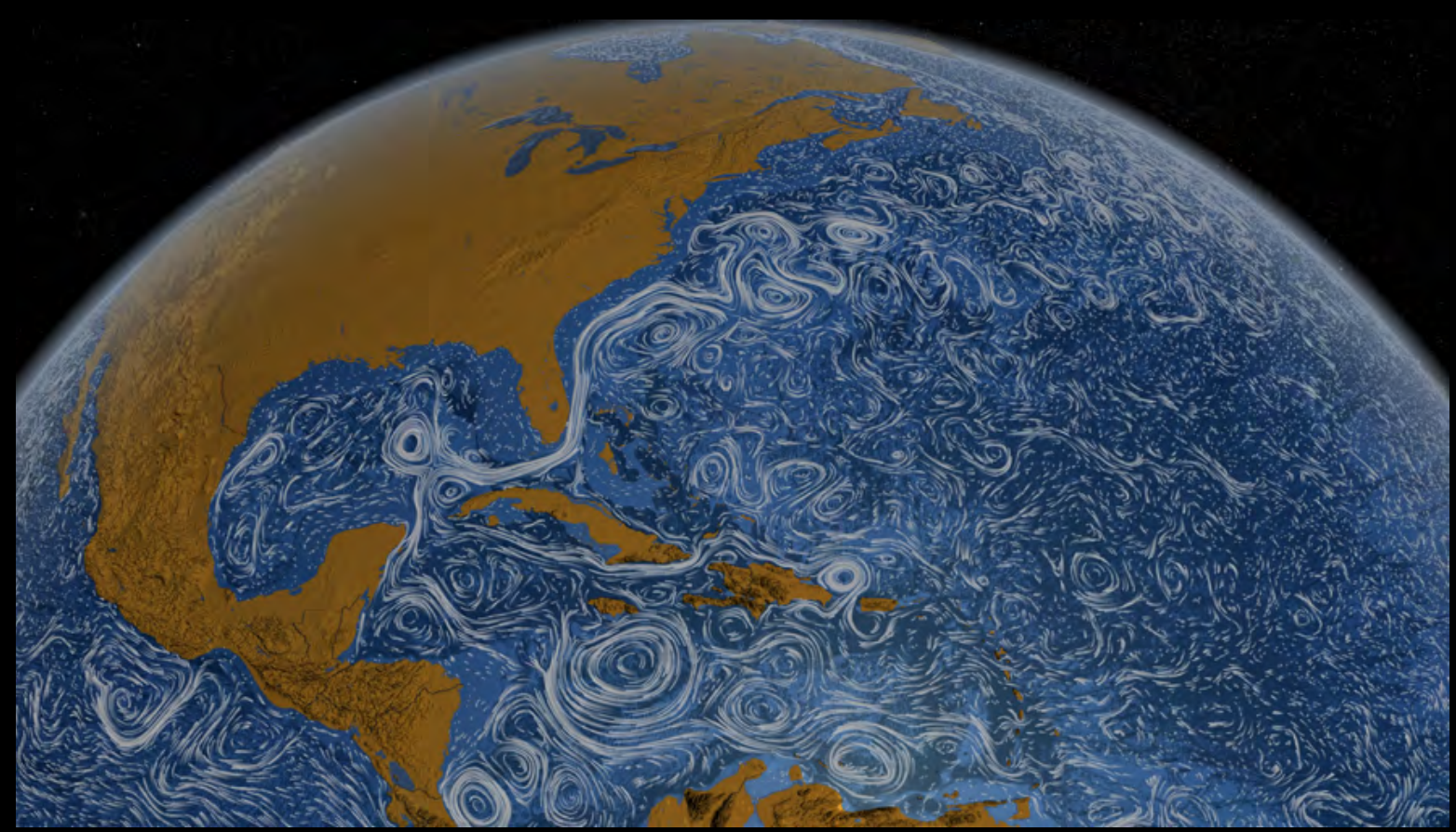

74

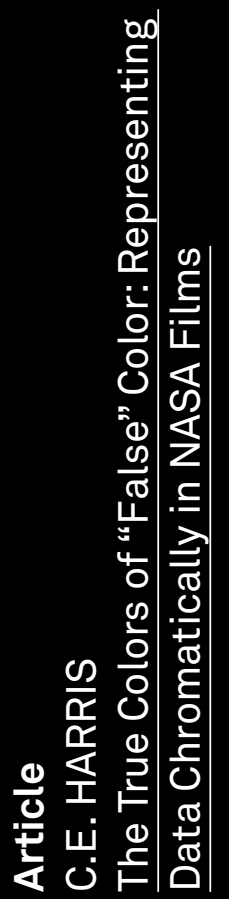

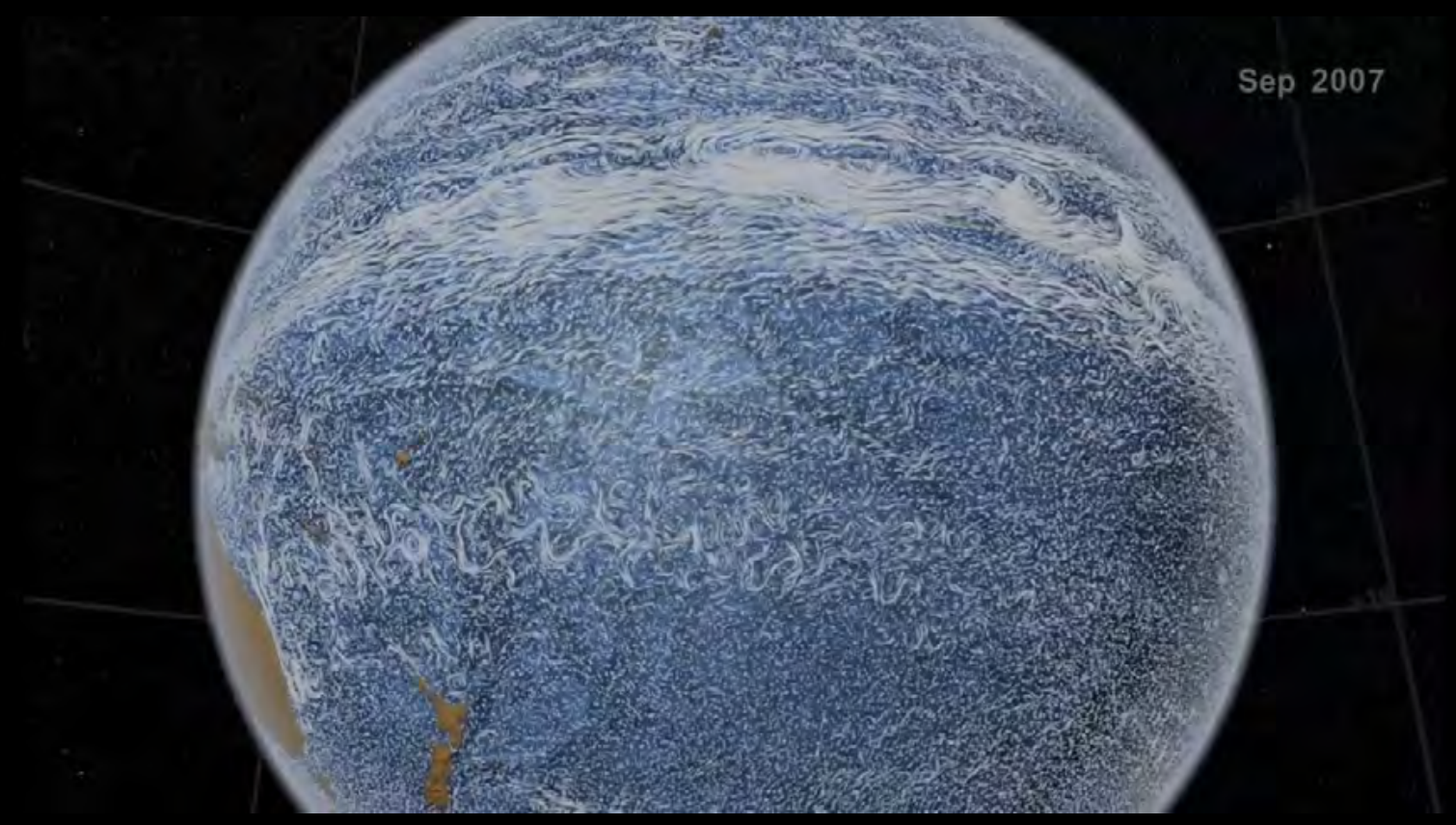

Fig. 8: The Earth in Perpetual Ocean (NASA/Goddard Space

Flight Center Scientific Visualization Studio, 2011)

\section{뜰 \\ s)}


film was a digital animation, this is even further pared down, more closely resembling Google Earth as if it were rendered by Van Gogh. The Earth appears in close up in the foreground, against a star-speckled black background demarcated by a grid of coordinates. The Earth slowly rotates to reveal the locations of specific areas of activity in the wind and ocean currents, which are visualized by swirling white and grey lines reminiscent of paintbrush strokes. Ocean-related data variables are shown using a spectrum of hues of blue, contrasted with orangebrown landmasses shown with basic topographic detail. As the visualization accelerates and takes us to various locations, swirls and strokes of color come to life, in different shapes, thicknesses, and lengths in accordance with the data points that animate them. Perpetual Ocean's aesthetic palette merges the digital with the painterly, and it is difficult to miss the visual and conceptual resonance with painting. In a 2001 panel entitled "Realism, Expressionism, and Abstraction: Applying Art Techniques to Visualization," Theresa-Marie Rhyne considers the possibilities that such painterly techniques could open up for the processing of data in scientific visualizations:

Non-photo realistic computer generated techniques explore distortions. Interested in neither reproducing the look of things, like the realist, nor in being specific about emotional reactions, like the expressionist, the abstractionist is interested in the world as a complex of ideas. If interested in trees, the abstractionist would ask what the idea of a tree might be and proceed to visually depict a pattern revealing that idea. Some mathematical relationships and the computer imagery associated with them are abstractions. (Rhyne et al. 2001, 523)

The animators who worked on Perpetual Ocean have explained how color in particular was a key factor in rendering the very complexity of its source data. Not only were the color choices motivated by naturalistic visual cues-blue for water, orangebrown for land, white for currents-but also factors such as tone, hue, and transparency/opacity were applied in order to render details of the numerical data in dynamic graphic form. At times, it goes beyond what is immediately visible to our eye and delves into precise measures that computers and subsequent visualization scientists can then register and re-transcribe, export, and apply in new contexts. In this way, Perpetual Ocean is not only a visualization of data, it is also a source of data that can be farmed to other ends later on. For example, data science and visualization specialist Andrew Leahy was able to use Perpetual Ocean as source data; by running it through further processing software and the Codelab plugin, he was able to "write routines to measure the saturation of a color and use this to control transparency" in order to create further interactive visualizations that can explore the data results proposed in Perpetual Ocean on other platforms like Google Earth (PlanetInAction, n.d.). Once again, color serves as a visual access point to data, providing it not only with an image, but also with a means of apprehending and comprehending its relation to other data sets, and with a narrative to reveal, explain and even predict realworld phenomena.

\section{Data as index in the digital age}

NASA data visualizer Robert Simmon has said that "the purpose of data visualization-any data visualization - is to illuminate data. To show patterns and relationships that are otherwise hidden in an impenetrable mass of numbers" (Simmon 2013). The data sets and digital tools used to create these 
visualizations bridge the gap between the realities that they represent and the plastic modes of observation that they engage. The potential loss of the primacy of the photographic image, with its indexical relationship to reality, or of the truth claim of realist aesthetics has brought about what is sometimes referred to as a "crisis" of the digital age. I would argue that these visualizations, with their turn toward digital animation and other contemporary techniques of plastic observation, represent a recommitment of sorts to the cinematic and to cinema's preoccupation with realism. They reveal the inherently constructionist nature of both science and cinema as they seek out and legitimize "experimental ways of knowing" through acts of observation (Messeri 2016, 12). By deferring their index from an imprint left by profilmic physical reality on the photochemical surface of film stock to the source data that gives rise to the images themselves, they contain, perhaps more than ever, the trace of reality at their core. With their animated, simulated, and translated visual elements, these visualizations engage in a sort of fabulation - a telling of the truth and a presentation of reality via the artifice of their vivid and spectacular colors - that has always been part of the project of cinema: presenting us with novel ways to engage with our world (and beyond) through images.

1/ See, for example, J.N. Vasquez, "Seeing Green" (2008), on the topic of how visual technology and aesthetics have affected the experience of war by shifting away from photorealistic images.

2/ This video is no longer available on the ScienceFriday.com website but can be found on YouTube as of the time of the writing of this article: https://www.youtube.com/ watch?v=RS99upE-dPs.

3/ This video was posted on December 12, 2014, but is no longer available due to the termination of the user's account. It exists, however, in archived form on the Internet Archive Wayback Machine, with captures made up through 2019: http://web.archive.org/ web/20190726173216if_/https://www.youtube.com/watch?v=4p_0bnICtDc.

4/ Richard Misek outlines this complex historiography in the introduction to his 2010 monograph, Chromatic Cinema: A History of Screen Color. In particular, he cites Tom Gunning's seminal article on the topic, "Colorful Metaphors: The Attraction of Color in Early Silent Cinema" (1995), which addresses early uses of film color in terms of the dichotomy of spectacle versus function.

5/ See in particular Rosalind Galt's Pretty: Film and the Decorative Image. In the introduction to this 2011 monograph, Galt levies an important critique against the reduction of qualities which may be perceived as "surface decoration"- such as prettiness or colorfulness - to mere "seduction" or "shallowness" $(2011,2)$.

6/ Original quote: “[...] Galilée, qui fut [...] le défenseur d'une coalescence nécessaire entre attitude esthétique et pensée scientifique." My translation.

7/ Original quote: “[...] la tradition galiléenne d'un art spatial pictural, naturaliste, figuratif et pittoresque qui artialise les contenus savants pour les rendre intelligibles à notre vue semble même se perpétuer." My translation.

8/ Original quote: "[qui] recourt à la fiction comme "véhicule cognitif [...]”. My translation.

9/ See for example, Richard Misek's Chromatic Cinema (2010), and especially his notion of digital color or "color as code" $(2010,12)$.

10/ See, in particular, Carolyn L. Kane's Chromatic Algorithms (2014).

11/ Tour of the Moon in 4K, created by David Ladd and Ernie Wright for NASA/Goddard Space Flight Center Scientific Visualization Studio. 2018; Web video. https://svs.gsfc.nasa. gov/4619 [accessed 23 October, 2021] 
12/ Cassiopeia A 3D Model: A Star from the Inside Out, created by NASA, the Chandra X-Ray Observatory Center, and D. Berry, using a model created by NASA, the Chandra X-Ray Observatory Center, MIT, and T. Delaney et al.. 2009; Web video. https://chandra.harvard. edu/photo/2009/casa2/ [accessed 23 October, 2021]

13/ Perpetual Ocean, created by Greg Shirah et al., for NASA/Goddard Space Flight Center Scientific Visualization Studio. 2011; Web video. https://svs.gsfc.nasa.gov/3827 [accessed 23 October, 2021]

\section{References}

Arcand, Kimberly Kowal. 2018. "Exploring Hidden and Exotic Worlds: How Astronomical Data Transports Us." Visualizing the Universe with NASA Data. Facilitated by Emma Marcucci for NASA's Universe of Learning Panel on Science Visualization. 12 April 2018. https://www.universe-of-learning.org/sciencebriefings/2018/4/10/visualizing-the-universe-with-nasa-data [accessed April 16, 2021]

Chandra X-Ray Observatory. 2009. "Cassiopeia A: 3-D Model: A Star from the Inside Out." Chandra X-Ray Observatory, 6 January 2009. https://chandra. harvard.edu/photo/2009/casa2/ [accessed June 1, 2019]

De Smet, Elsa. 2017. “Les piliers de la création, ou les mutations de l'art spatial." Artpress2: Images de l'espace - Archive, exploration, fiction 44: 21-24.

Doane, Mary Ann. 2007. "Indexicality: Trace and Sign: Introduction." Differences 18(1): 1-6. https://doi.org/10.1215/10407391-2006-020

ECCO Group. 2007. "Content of ECCO for LAS/Obs." Data Set Parent Directory, OPeNDAP. http://mit.ecco-group.org/opendap/ecco_for_las/obs/contents.html [accessed May 15, 2019].

Fan, Ying. 2015. "Groundwater in the Earth's Critical Zone: Relevance to LargeScale Patterns and Processes: Groundwater at Large Scales." Water Resources Research 51(5): 3052-69. https://doi.org/10.1002/2015WR017037

Feldman, Gene, and Rob Simmon. 2012. "Science Friday Explains the Blue Marble." Interview by Flora Lichtman. Earth Observatory: Elegant Figures, 7 February 2012. Video. https://earthobservatory.nasa.gov/blogs/ elegantfigures/2012/02/07/science-friday-explains-the-blue-marble/ [accessed July 29, 2021].

Galt, Rosalind. 2011. Pretty: Film and the Decorative Image. New York: Columbia University Press.

Humanités Spatiales (CNES), n.d. Le Blog des Humanités Spatiales. http:// humanites-spatiales.fr [accessed June 1, 2019].

Hurt, Robert. "The Art of Science Visualization." Visualizing the Universe with NASA Data. Facilitated by Emma Marcucci for NASA's Universe of Learning Panel on Science Visualization. 12 April 2018. https://media.universe-of-learning.org/ documents/UoL_SciBriefing_2018-04-12-transcript.html [accessed April 16, 2021].

Johnson, William. 1966. "Coming to Terms with Color." Film Quarterly 20(1): 2-22. https://doi.org/10.2307/1211158 
Kane, Carolyn L. 2014. Chromatic Algorithms: Synthetic Color, Computer Art, and Aesthetics after Code. Chicago \& London: The University of Chicago Press. https://doi.org/10.7208/chicago/9780226002873.001.0001

Messeri, Lisa. 2016. Placing Outer Space: An Earthly Ethnography of Other Worlds. Durham: Duke University Press. https://doi.org/10.2307/j.ctv11cw9f7

Miro, Todd. 2010. "Teal and Orange - Hollywood, Please Stop the Madness." Into the Abyss (blog), 14 March 2010. http://theabyssgazes.blogspot. com/2010/03/teal-and-orange-hollywood-please-stop.html [accessed April 8, 2021].

Misek, Richard. 2010. Chromatic Cinema: A History of Screen Color. Chichester, UK: Wiley-Blackwell. https://doi.org/10.1002/9781444320077

NASA. 2012. "NASA Views Our Perpetual Ocean.” NASA: Earth, 9 April 2012. http://www.nasa.gov/topics/earth/features/perpetual-ocean.html [accessed April 15, 2021].

NASA Jet Propulsion Laboratory. 2005. "Embryonic Stars Emerge from Interstellar 'Eggs'." NASA Jet Propulsion Laboratory online. 2 November 2005. https://www.jpl.nasa.gov/images/embryonic-stars-emerge-from-interstellareggs [accessed July 28, 2021].

PlanetInAction. n.d. "Perpetual Ocean Demo." http://web.archive.org/ web/20190322023637/ http://www.planetinaction.com/currents/ [accessed April 15, 2021].

Rector, Travis A., Kimberly Arcand, and Megan Watzke. 2015. Coloring the Universe: An Insider's Look at Making Spectacular Images of Space. Fairbanks: University of Alaska Press.

Rhyne, Theresa-Marie, et al. 2001. "Realism, Expressionism, and Abstraction: Applying Art Techniques to Visualization." Vis '01: Proceedings of the IEEE Computer Society's 2001 Conference on Visualization (October): 523-52.

Simmon, Robert. 2013. "Elegant Figures - Subtleties of Color (Part 1 of 6)." Earth Observatory: Elegant Figures, 5 August 2013. https://earthobservatory. nasa.gov/blogs/elegantfigures/2013/08/05/subtleties-of-color-part-1-of-6/ [accessed October 31, 2021].

Vasquez, J.M. 2008. “Seeing Green." Social Analysis 52(2): 87-105. https://doi. org/10.3167/sa.2008.520206

How to reference Harris, C.E. 2021. "The True Colors of "False" Color: Representing Data Chromatically in NASA Films." Comparative Cinema, Vol. IX, No. 17, pp. 57-78. DOI: 10.31009/cc.2021.v9.i17.04 